\title{
SOME ANALYSES OF MILK AND THE DETERMINATION OF MILK SUGAR.
}

Bx C. W. Stephens, F.C.S.

Read before the Society at the meeting on the 17th Decernber, 1884.

THEse experiments were undertaken in the hope of slightly aiding the Milk Committee of the S. P. A. ; also (at the suggestion of Mr. Kingzett) to ascertain if it is practicable to estimate milk sugar without first separating the caseine. If this can be done, not only will time be saved in the analysis of milk, but it is possible that the estimation of the lactose in milk may serve as an additional standard for determination of purity and adulteration. The "total solids not fat" have not been estimated.

The cream was estimated in a glass cylinder capable of holding 100 c.c., and graduated to one c.c., by allowing the milk to stand in the measure during 24 hours. I find the cream comes up best, when 50 c.c. of the milk are run into the cylinder, and then filled up with water to the 100 c.c. mark.

The specific gravity was taken by weight (with the exception of the nirst three, in which cases it was taken by the hydrometer) using a sp. gr. bottle of 25 c.c. capacity, and a "Becker's balance," indicating half a milligramme. The "total solids" were estimated by evaporation in a platinum dish, until the weight was constant. After several trial experiments, in which the caseine was first precipitated in the usual manner and removed before the estimation of the milk sugar, I found that, if from 6 to 8 grammes of the milk be carefully weighed in a tared beaker, and then made up to 100 c.c. with water, the sugar can be estimated at once without the separation of the caseine. The method $I$ have adopted is as follows:-

Twenty-five (25) c.c. of "Fehling's solution" (34.65 grammes of sulphate of copper dissolved in 200 c.c. water and mixed with a solution containing 173 grammes of double tartrate of potassium and sodium in 480 c.c., caustic soda solution of sp. gr. 1.14, 
and the mixture made up the one litre) is taken and placed in a beaker or porcelain dish ; when boiling, the milk solution is run in from a burette (graduated to 2 c.c.) until decolourisation is nearly effected, the solution being tested, as usual, from time to timo, with potassium ferrocyanide, and addition of the milk solution continued until the mixture ceases to give the red colouration. Most of the results have been controlled by the gravimetric process, which was conducted as follows :-A slight excess of tho "Fehling's solution" was boiled; a known quantity of the milk solution was then added; the precipitate was filtered off, well washed in order to remove the excess of copper solution, and then dissolved on the filter with hot dilute nitric acid, the coppcr being afterwards procipitated in the usual way, with caustic soda, roasted in a porcelain crucible and weighed as cupric oxide. I have found that the two processes give fairly accordant results. The ash was estimated by burning the "total solids" in a platinum dish; the solids and the ash being determined in duplicate. The lactose was checked as said, or by a duplicate volumetric estimation, 10 c.c. of the copper solution have been estimated as equal to 0.067 gramme milk sugar, dried at $100^{\circ} \mathrm{c}$. I also tested the "Fehling's solution" against pure lactose. I will now give an example of the method followed for determining the lactose :-6.743 grammes mill were diluted with water to 100 c.c. ; 58 c.c. of the millk solution were found necessary to reduce 25 c.c. copper solution $\therefore \frac{25 \times 100}{58}=43.1034$ copper solution required for the 6.743 grammes milk, $\therefore$ the value in lactose for 100 grammes milk $=\frac{.67 \times 43.1034}{6.743}=4.28$ grammes lactose.

\begin{tabular}{|c|c|c|c|c|c|c|c|c|}
\hline \multirow{2}{*}{ 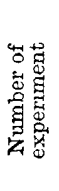 } & \multirow{2}{*}{ 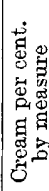 } & \multirow{2}{*}{$\begin{array}{l}\text { Sp. gr. } \\
\text { corrected } \\
\text { to } 60^{2} \mathrm{~F}\end{array}$} & \multirow{2}{*}{$\begin{array}{c}\text { Total } \\
\text { solids } \\
\text { dried to } \\
\text { constancy }\end{array}$} & \multicolumn{2}{|c|}{$\begin{array}{l}\text { Lictose gravi- } \\
\text { metrically }\end{array}$} & \multirow{2}{*}{$\begin{array}{c}\text { Lactose } \\
\text { deter- } \\
\text { mined } \\
\text { volu- } \\
\text { metrically }\end{array}$} & \multirow{2}{*}{$\begin{array}{c}\text { Ash } \\
\text { per cent. } \\
\text { by weight }\end{array}$} & \multirow[b]{2}{*}{ Remarks } \\
\hline & & & & $\begin{array}{c}\text { Copper } \\
\text { oxide, } \\
\text { per cent., } \\
\text { werghed }\end{array}$ & $\begin{array}{c}\text { Tactose } \\
\text { calculated } \\
\text { there- } \\
\text { from }\end{array}$ & & & \\
\hline & & $\begin{array}{l}\text { By hydro- } \\
\text { nucter: }\end{array}$ & & & & & & \\
\hline$t$ & 11 & 10317 & $12 \cdot 75$ & $7 \cdot 67.5$ & $4 \cdot 61$ & .. & $\cdot 69$ & No. 1 , evening's milk, authenticated. \\
\hline 2 & 8 & $1 \cdot 0304$ & $12 \cdot 20.5$ & $7 \cdot 527$ & 4.569 & .. & $\cdot 71$ & No. 1, morning's milk, authenticated. \\
\hline 3 & 13 & Congu. & $14 \cdot 122.5$ & $6 \cdot 8041$ & $4 \cdot 1 \geq 9$ & .. & $\cdot 86$ & No. 2, evening's milk, authenticated. \\
\hline 4 & 8 & 1.0389 & $12 \cdot 1375$ & $6 \cdot 90529$ & $4 \cdot 1901$ & . & $\cdot 77$ & No. 2, done again because of coagn. \\
\hline$j$ & 24 & $\begin{array}{l}\text { By uelght } \\
\text { 1.03414 } \\
\text { weighed }\end{array}$ & $14 \cdot 8869$ & $6 \cdot 7.522$ & $4 \cdot 098$ & .. & $\cdot 77$ & $\begin{array}{l}\text { No. 3, near calving, do not give much } \\
\text { milk, morning, authenticated. }\end{array}$ \\
\hline 6 & 23 & 103117 & 147159 & $7 \cdot 8682$ & 1.776 & +1423 & 808 & No. 3, evening's milk, authenticated. \\
\hline 7 & 12 & $1 \cdot 02712$ & $12 \cdot 8688$ & $6 \cdot 447$ & 39 & & 7 & $\begin{array}{l}\text { No. 4, evening's milk, lately losing } \\
\text { flesh, but no particular sign of } \\
\text { disease, authonticated. }\end{array}$ \\
\hline 8 & 12 & $1 \cdot 03053$ & $12 \cdot 87$ & $7 \cdot 0347$ & $4 \cdot 27$ & 4.53 & 836 & No. 5, morning's milk, authenticated. \\
\hline 9 & 11 & $1 \cdot 0276.5$ & $13 \cdot 88 ?$ & Lost & & $4 \cdot 1946$ & & No. 5, evening's milk, authenticated. \\
\hline 10 & 12 & 102538 & $14 \cdot 6142$ & $7 \cdot 4927$ & $4 \cdot 581$ & 4.548 & & Ditto $\quad$ ditto. \\
\hline 11 & 10 & not taken & $12 \cdot 081$ & $7 \cdot 2371$ & $4 \cdot 39303$ & $4 \cdot 2728$ & 698 & From a herd, unauthenticated. \\
\hline 12 & 12 & 102944 & $12 \cdot 629$ & omit & ted & $4 \cdot 5604$ & $\cdot 725$ & No. 6, morning's milk, authenticated. \\
\hline 13 & 12 & $1 \cdot 02838$ & $12 \cdot 199$ & omit & & $4 \cdot 16204$ & $\cdot 74$ & From a berd, unauthenticated. \\
\hline 14 & 16 & 1.03228 & $12 \cdot 99315$ & $6 \cdot 6922$ & $4 \cdot 0622$ & $4 \cdot 208$ & $\cdot 708$ & No. 7 morning, authenticated. \\
\hline 1.5 & 12 & $1 \cdot 02947$ & $13 \cdot 4225$ & omit & ted & 4.77174 & $\cdot 710$ & From a herd, unauthenticated. \\
\hline 16 & 22 & $1 \cdot 025,56$ & $14 \cdot 112$ & omit & ted & $4 \cdot 08829$ & $\cdot 6638$ & No. 7, evening's milk, authenticated. \\
\hline
\end{tabular}


Tho numbers 1, 2, 3, \&c., given in the remarks in the table of analyses, refer to individual cows, numbered in that way by the milkman and myself to distinguish each cow. The cows so marked are fairly fed, all under seven years of age. The milk marked from a "herd" is the only mixed milk. "Authenticated," of course means it is known to be genuine, and "unauthenticated," means there is not that certain knowledge ; although the samples appear to be genuine frum the analyses, saving that some cream may possibly have been removed. As to the determination of lactose by the gravimetric process, I am not perfectly satisfied with the results, because I have had to do the analyses in broken periods of time; I am sure, however, that the results of the gravimetric and volumetric processes could be brought more into accordance. It may be useful to note that, if any "standard" be adopted for milk sugar, it would be useful to use the number 600 c.c. as representing the minimum of "Fehling's solution" that should be required per 100 grammes of milk, this would be better than using a per-centage of lactose, because the number 600 is comparatively large. "What I mean is, it takes about 600 c.c. of the copper solution for the 100 grammes of milk; thus we get the factors $\frac{6 \times 67}{100}=4.02$ lactose.

In calculating from the results of the gravimetric process, I have taken the value of the cupric oxide in terms of lactose from 0.067 gramme per 10 c.c. of "Fehling's solution." Example:-cupric oxide found $=0.595$ gramme for 8.458 grammes milk $\therefore \frac{59 j \times 100}{8 \cdot 458}=7.0347$ grammes, cupric oxide for 100 grammes milk; but what is the value of this in terms of lactose?

From the knowledge that 79.5 grammes $\mathrm{CuO}$ are reduced by 6.7 grammes lactose, we learn by calculation that 7.034 grammes $\mathrm{CuO}$ (got by oxidation of the reduced $\mathrm{Cu}_{2} \mathrm{O}$ ) is equivalent to 4.2 lactose.

\section{DISCUSSION.}

Mr. KINGZETT said:- In the ordinary course of professional work, I have been in the habit of estimating the milk sugar volumetrically, and without first precipitating the caseine, as I found this to be unnecessary. The agreenent between the volumetric and gravimetric determinations made by $\mathrm{Mr}$. C. W. Stephens is not so entire as could be wished, owing partly, in all probability, to the fact that the work was conducted in broken periods of time and not continuously. At the same time the results approximate sufficiently to show that milk sugar may be accurately estimated by the direct titration of the diluted whole milk. That being so, I think chemists should pay as much attention to this factor, in the determination of the purity or adulteration of milk, as to other factors. At least, as regards watering of milk, the evidence to be obtained by determining the sugar is as important as that furnished by the ash, and certainly more valuable than that of fat and total solids. I can give a case in point which relates to a watered milk supplied to my own household. 
The specific gravity of the milk (taken by weight) was 1.025 .

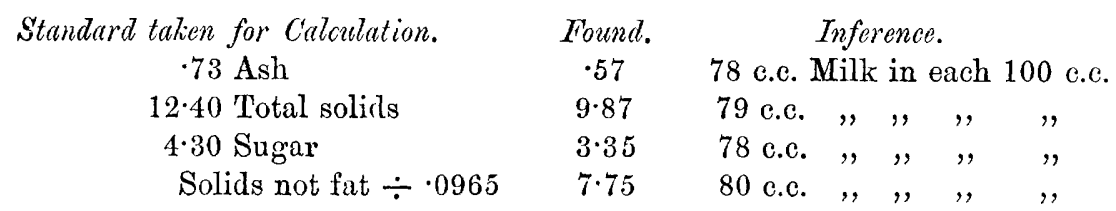

I am aware that some chemists determine milk sugar by precipitating the caseine and weighing the suboxide of copper obtained in the volumetric process, but I should. be very strongly inclined to question the accuracy of this method, since the reduced oxide in the presence of alkali very readily absorbs oxygen and becomes converted into the higher oxide. So long ago as in $1872 *$ I showed that the precipitate obtained by reduction of cupric sulphate with sugar in the presence of potassic hydrate, after wash. ing and drying, is not free from cupric oxide and that the whole of it may be effectually converted into cupric oxide by suspending it in water rendered slightly alkaline, and passing a current of air through the mixture for a few hours. I am satisfied, therefore, that, considering the rapidity of this change and the considerable extent to which the suboxide of copper is exposed to the action of the atmosphere during filtration and washing (while alkali is still present), perfectly accurate results could not be obtained. If it be desired to employ a gravimetric method, the suboxide must be converted wholly into the higher oxide and weighed as such. It would be probably an improvemen upon the method followed by Mr. Stephens, to separate, wash, and dry the cuprous oxide, and convert it finally into cupric oxide by merely moistening it with strong nitric acid, followed by ignition in a platinum crucible.

Dr. Durnè said that the estimation might, of course, be of considerable value, but there were very strong rensons for supposing that the amount of milk sugar in milk was not even fairly constant. It was not an uncommon thing to have two samples of milk perfeotly genuine, of which one might have twice as much milk sugar as the other. Two years ago he read a paper, giving some experiments, in which the amount of milk sugar varied to an enormous extent. It would require a very large number of experiments to get out any reliable data.

Mr. Alten described a method for the determination of milk sugar communicated to him by Professor S. P. Sharples, of Boston, U.S.A. The process consisted in treating 65 grammes of the sample of milk with 5 c.c. of the solution of basic acetate of lead employed for clarifying sugar solutions. The mixture was shaken, the liquid diluted to 100 c.c., and at once filtered through a dry filter. If properly done, the treatment produced a perfectly clear filtrate, which gave no precipitate on boiling. The essential condition was to employ no heat, or effectual filtration became impossible. A 2-decimetre tube was then filled with the clear solution, and the rotation observed with a polarimeter. With an instrument employing white light, and constructed for use with 26.048 grammes of cane sugar, half the number of sugar-units of rotation gave the

\footnotetext{
* Chemcal News, January 5, 1872.
} 
grammes of hydrated milk sugar in 100 c.c. of the milk.* The whole operation occupied from 12 to 15 minutes. Mr. Allen suggested that, besides being useful as a means of estimating milk-sugar, the process might probably be advantageously employed for the extraction of the fat, as it would merely be necessary to dry the filter, and treat it in a Soxhlet's tube. A few experiments he had made in this direction had given very encouraging results.

Coxchuston of the Proceedrags of the Society.

$\div$ Strictly speaking, the amount of milk which should be employed with such an instrument is 65.7 grammes, or 64 c.c. If the instrument be one intended for use with sodium light (the standard weight of sugar being 26.048 grammes as before), 7027 grammes (or 68 c.o.) of milk should be employed, when each curalla degree of rotationfwill correspond to 1.5 grammes of milk-sugar in 100 c.c. of the sample. If 16.35 grammes be the standard weight of sugar intended to be used with the instrument, the most conrenient quantity of milk to employ is 61.62 grammes $(=60$ c.c.) when one-third of the cane-sugar-units indicated will be the number of grammes of milk-sugar in 100 c.c. of the sample.-A. HrLIs. 